\title{
Seismic dynamo effects associated with the M7.1 earthquake of 26 May 2003 off Miyagi Prefecture and the M6.4 earthquake of 26 July 2003 in northern Miyagi Prefecture, NE Japan
}

\author{
Yoshimori Honkura $^{1}$, Hideyuki Satoh ${ }^{2}$, and Naoto Ujihara ${ }^{1}$ \\ ${ }^{1}$ Department of Earth and Planetary Sciences, Tokyo Institute of Technology, Tokyo, Japan \\ ${ }^{2}$ AIST, Tsukuba, Japan \\ (Received October 31, 2003; Revised January 25, 2004; Accepted January 29, 2004)
}

\begin{abstract}
An earthquake of M7.1 occurred off Miyagi Prefecture, NE Japan, on May 26, 2003 at the depth of about $70 \mathrm{~km}$. Just two months later, on July 26, 2003, another shallow earthquake of M6.4 occurred in northern Miyagi Prefecture. In order to investigate whether small signals precursory to the arrival of seismic wave appeared for these earthquakes, we examined the MT records which have continuously been acquired at two stations, Mizusawa and Esashi of the Geographical Survey Institute, located about $50 \mathrm{~km}$ northwest of the epicenter of the M7.1 earthquake and about $100 \mathrm{~km}$ north of the M6.4 earthquake. Unfortunately, seismometers were not available at these stations, and hence direct comparison between the MT and the seismic records were not possible. We therefore refer to the seismic record obtained at a nearby station belonging to the nation-wide seismic network called 'Hi-net' and also we used the arrival times estimated by Japan Meteorological Agency (JMA) for these MT stations. In conclusion, no clear signals preceding the arrival of seismic wave could be detected, although the possibility is suggested that a slight signal may have appeared in one magnetic component at the Mizusawa station before the arrival of seismic wave for the M7.1 earthquake.
\end{abstract}

Key words: Seismic dynamo effect, magnetotellurics, electric and magnetic field variation, seismic wave.

\section{Introduction}

Since the finding of electric and magnetic field variations due to the so-called seismic dynamo effect in the case of the 1999 Izmit earthquake in northwestern Turkey (Honkura et al., 2000, 2002), we have tried to make magnetotelluric (MT) observations on various occasions (Matsushima et al., 2002; Ujihara et al., 2004). In some cases, seismic observations were also made simultaneously with MT observations. Although electric and magnetic variations could always be observed in association with seismic wave passage and hence the observational evidence showing the seismic dynamo effect has been accumulated, no clear signals precursory to the arrival of seismic wave have been obtained.

As was shown in Honkura et al. (2002), precursory signals turned out to be small and hence they would be detected only for strong ground velocity and thus for a large earthquake occurring close to the MT observation site. In fact, for small earthquakes, electric and magnetic signals due to the seismic dynamo effect were small and possible precursory signals should be much smaller than the noise level (Matsushima et al., 2002; Ujihara et al., 2004).

In this respect, the earthquakes which occurred on May 26, 2003 and on July 26, 2003 are fairly large, JMA (Japan Meteorological Agency) magnitude 7.1 and 6.4, respectively. Also, electric and magnetic field variations associated with these earthquakes were successfully recorded as the contin-

Copy right (c) The Society of Geomagnetism and Earth, Planetary and Space Sciences (SGEPSS); The Seismological Society of Japan; The Volcanological Society of Japan; The Geodetic Society of Japan; The Japanese Society for Planetary Sciences; TERRAPUB uous time-series data of electric and magnetic field variations at two MT stations of the Geographical Survey Institute. Therefore, we tried to examine whether precursory signals can be seen in the MT records, although the hypocentral distance to the MT stations turned out to be fairly long, about $100 \mathrm{~km}$ for both the earthquakes, as shown in Fig. 1.

\section{MT Observation Sites}

Figure 1 shows the locations of two MT observation sites where two components of the electric field and three components of the magnetic field have been continuously recorded by the Geographical Survey Institute. Although no seismic records are available at the MT sites, there are some seismic stations belonging to the nation-wide network called the 'Hi-net', and seismographs could be used for this study. In particular, the station denoted by SMT in Fig. 1 is very close to the site, Esashi, and hence we can compare the MT records with the seismographs.

The sampling rate for continuous MT observations is 24 $\mathrm{Hz}$ which is fairly slower than that for seismic records, 100 $\mathrm{Hz}$, but this is not very crucial in view of errors in the arrival time estimation for the area including three Hi-net stations shown in Fig. 1; the estimated errors are $-0.1-+0.1$ sec for the M7.1 earthquake and $-0.3--0.1$ for the M6.4 earthquake.

\section{Results}

3.1 The M7.1 earthquake of May 26

Figure 2 shows the electric and the magnetic field variations at Mizusawa and Esashi, respectively. One notable fact 


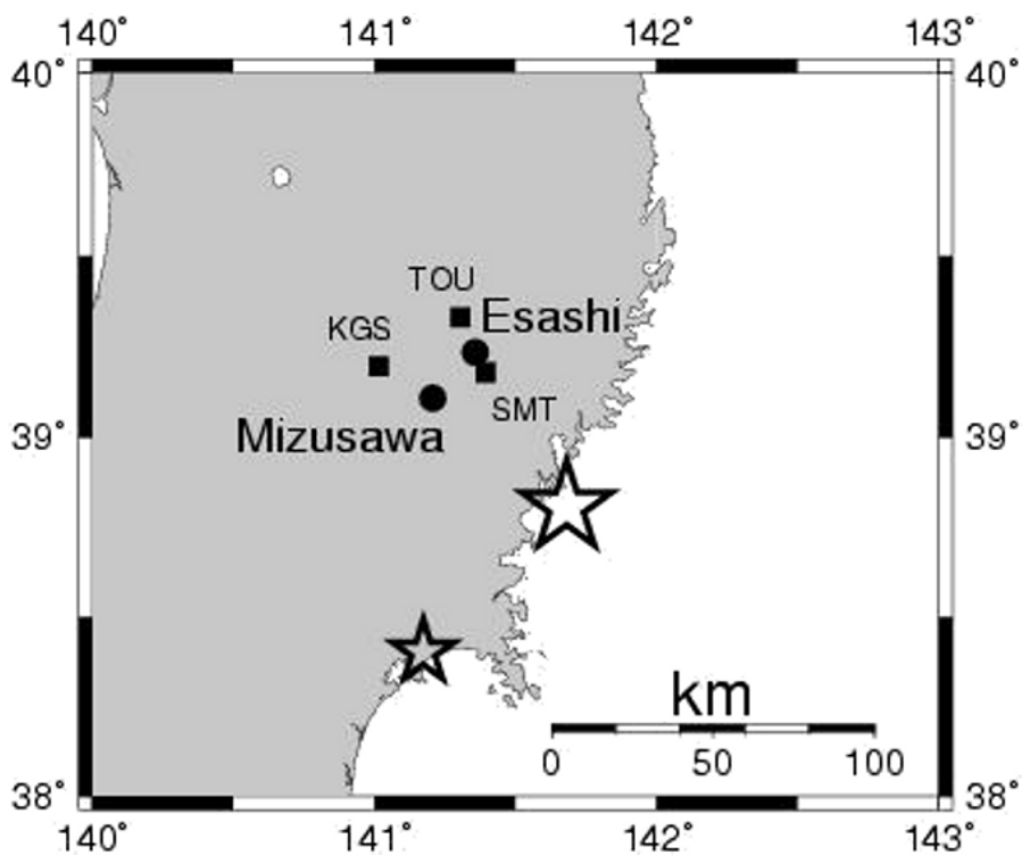

Fig. 1. Locations of the MT stations, Mizusawa and Esashi, and the Hi-net seismic stations, SMT, TOU, KGS. A large star symbol indicates the epicenter of the M7.1 earthquake of 26 May 2003 and a small star symbol the epicenter of the M6.4 earthquake of 26 July 2003.
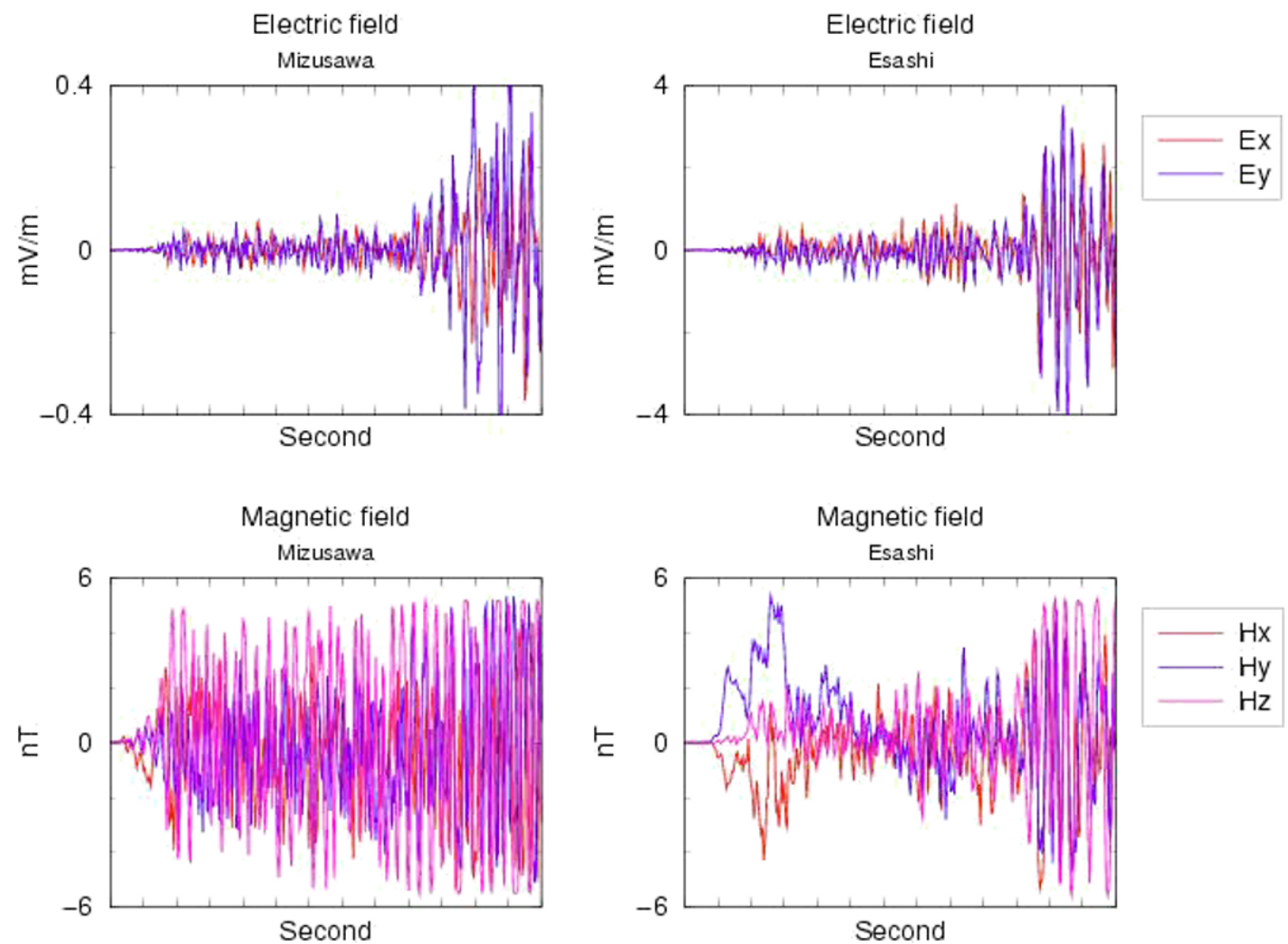

Fig. 2. Electric $\left(E_{x}, E_{y}\right)$ and magnetic $\left(H_{x}, H_{y}, H_{z}\right)$ field records, where $x$ refers to the magnetic north for Esashi and the direction of 35 degrees west from the magnetic north for Mizusawa, $y$ to the east for Esashi and the direction 55 degrees east from the north for Mizusawa and $z$ to the downward direction, obtained at Mizusawa and Esashi in association with the M7.1 earthquake. The unit of the abscissa is one second. 


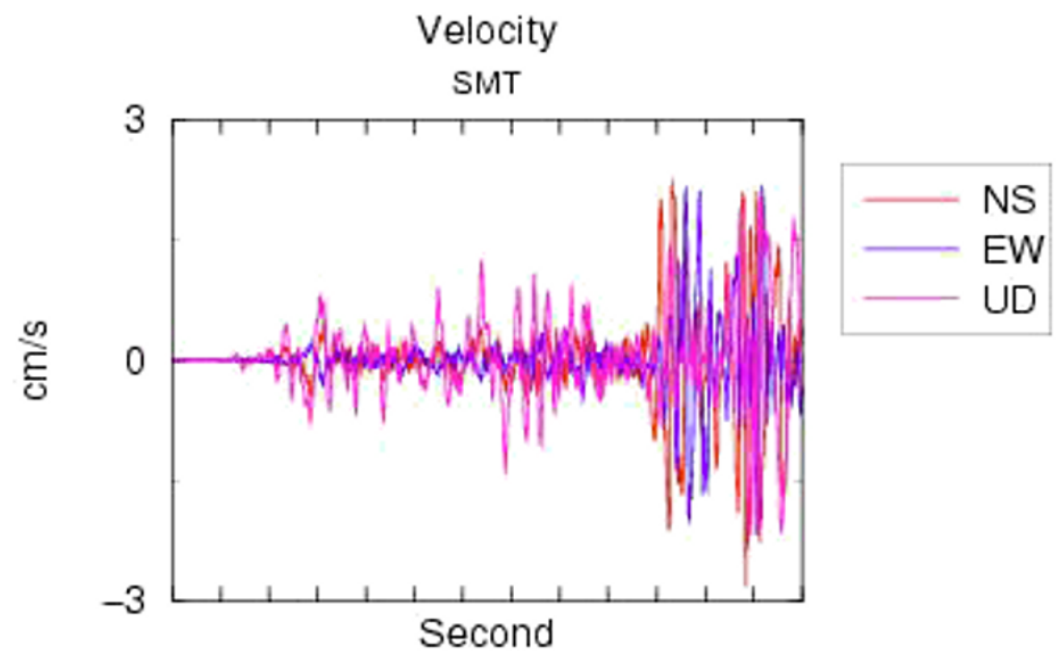

Fig. 3. The N-S, E-W and U-D components of ground velocity at SMT for the M7.1 earthquake. The unit of the abscissa is one second.
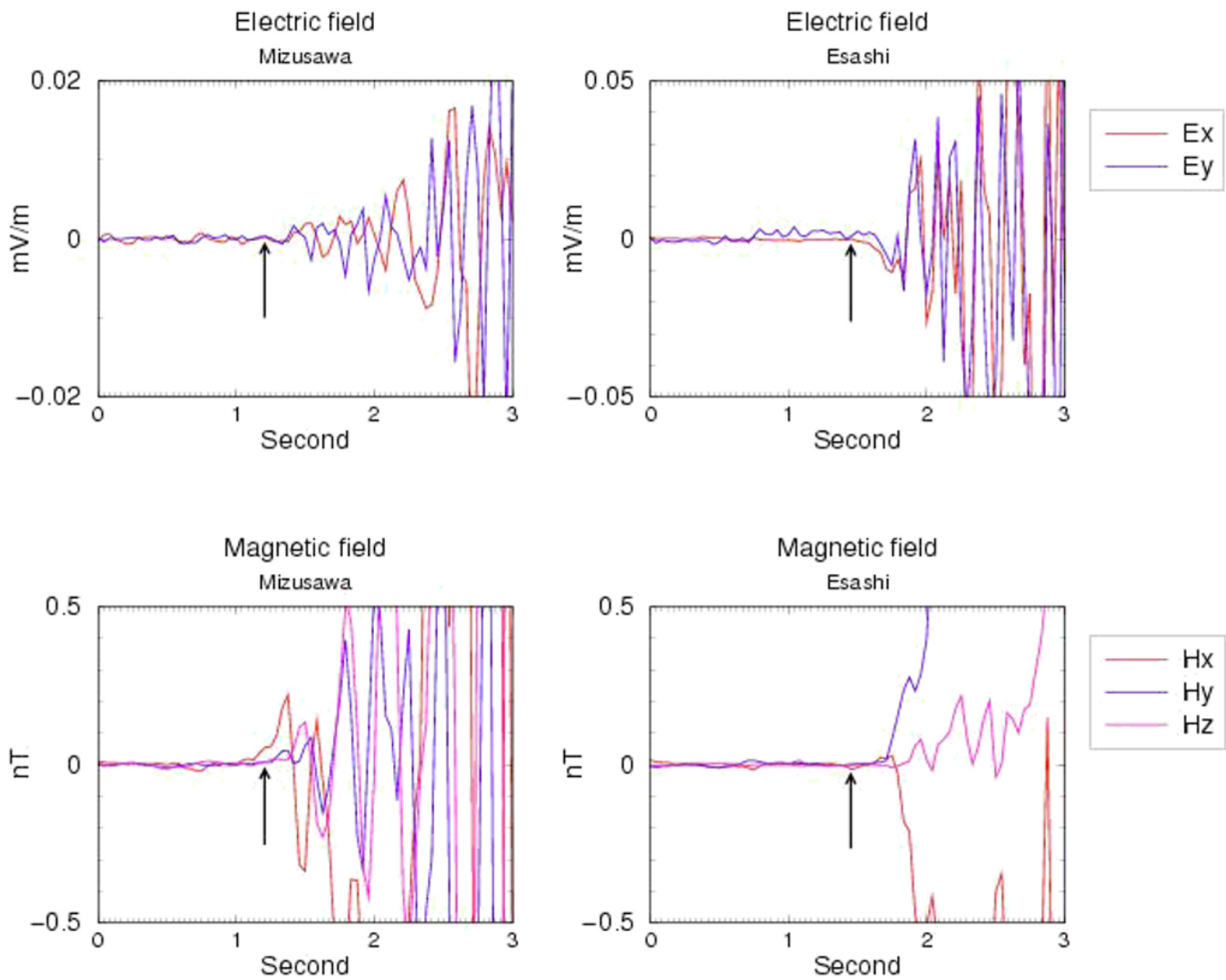

Fig. 4. Close-up views of Fig. 2. The arrow indicates the estimated P-wave arrival time for the M7.1 earthquake. Small tick marks indicate the sampling times of the electric and the magnetic fields.

is that the electric field is one order of magnitude smaller at Mizusawa than at Esashi, whereas the magnetic field is larger at Mizusawa. It is unlikely that the ground velocity is one order of magnitude different between the two stations, as can be inferred from the epicentral distances and also from the comparison between seismograms at three nearby stations (Fig. 1).

In MT, it is well known that the electric field is sensitive 

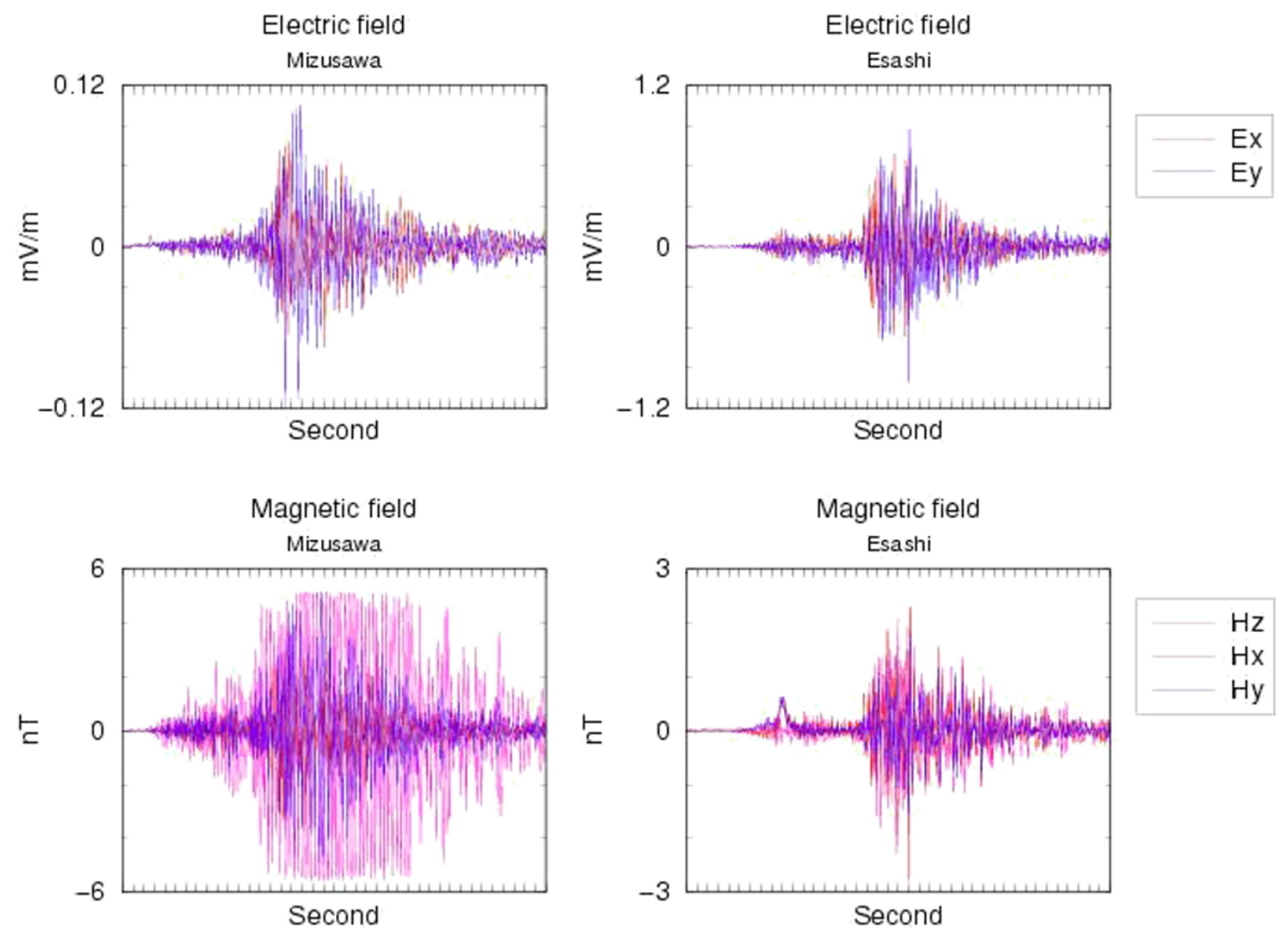

Fig. 5. Electric $\left(E_{x}, E_{y}\right)$ and magnetic $\left(H_{x}, H_{y}, H_{z}\right)$ field records obtained at Mizusawa and Esashi in association with the M6.4 earthquake. The unit of the abscissa is one second.

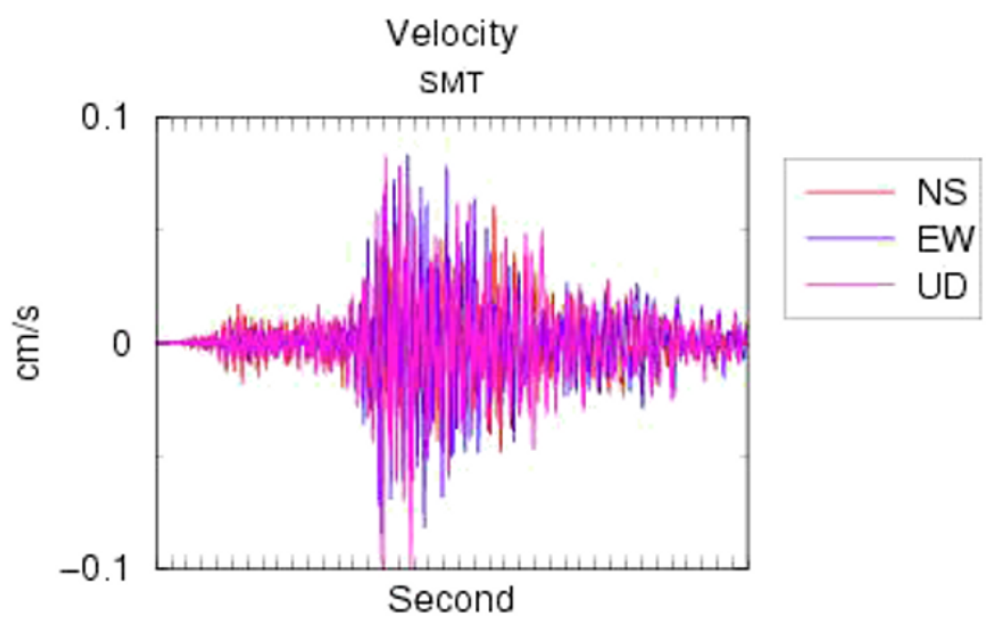

Fig. 6. The N-S, E-W and U-D components of ground velocity at SMT for the M6.4 earthquake. The unit of the abscissa is one second.

to the local resistivity structure and the amplitude tends to be smaller for low resistivity structure. In fact, the apparent resistivity for the frequency range between 1 and $10 \mathrm{~Hz}$ is about $100 \mathrm{ohm} \cdot \mathrm{m}$ at Mizusawa and about 1,000 ohm.m at Esashi (Satoh et al., 2003). This is quite consistent with the amplitudes of electric field signals due to the seismic dynamo effect, confirming that the effect is in fact an electromagnetic induction phenomenon. It should be noted that the magnetic field is clipped during $\mathrm{S}$ waves at both the stations. Some strange variations seen in the magnetic filed at Esashi after the P-wave arrival would be instrumental effects.

Figure 3 shows three components of the velocity field at SMT, which are very similar in overall shape to the electric and magnetic fields at the MT stations, also confirming the seismic dynamo effect associated with the M7.1 earthquake.

Figure 4 shows the close-up views of Fig. 2. The arrow 

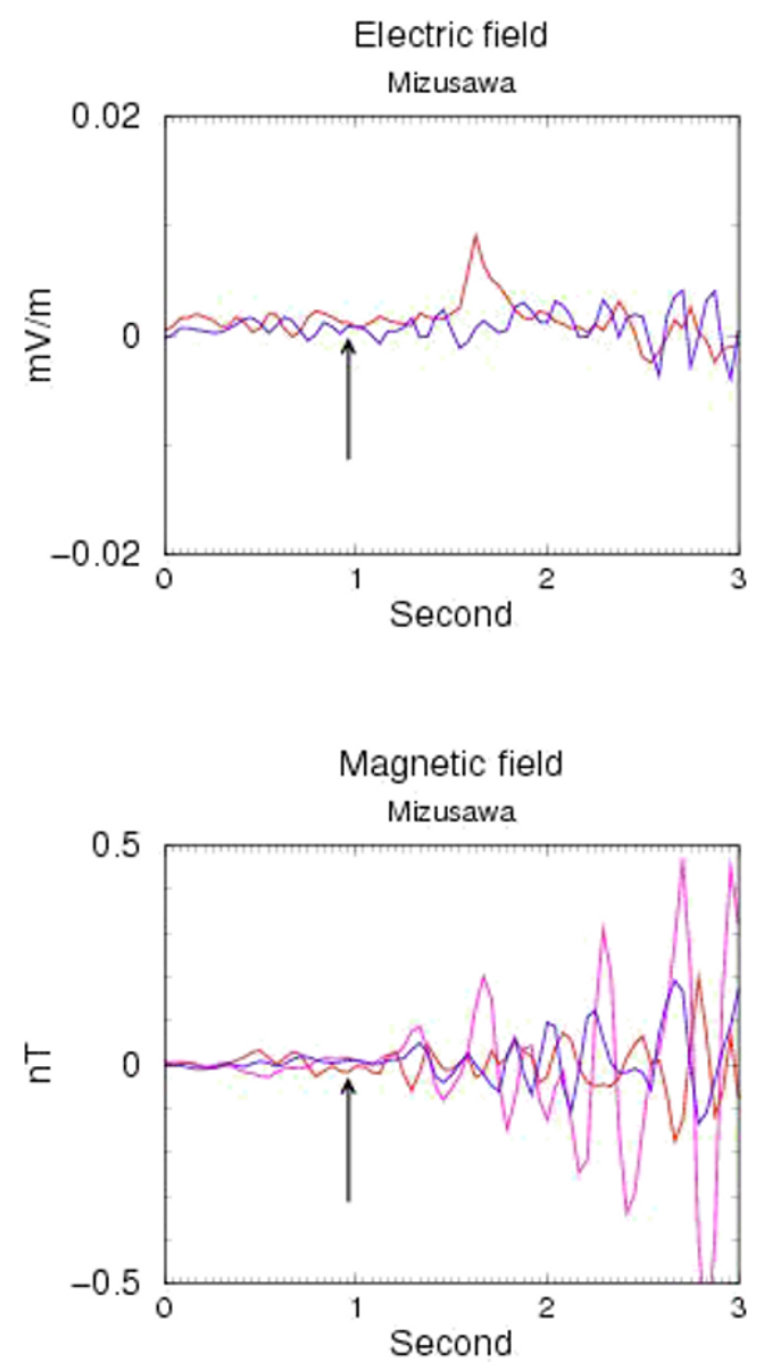
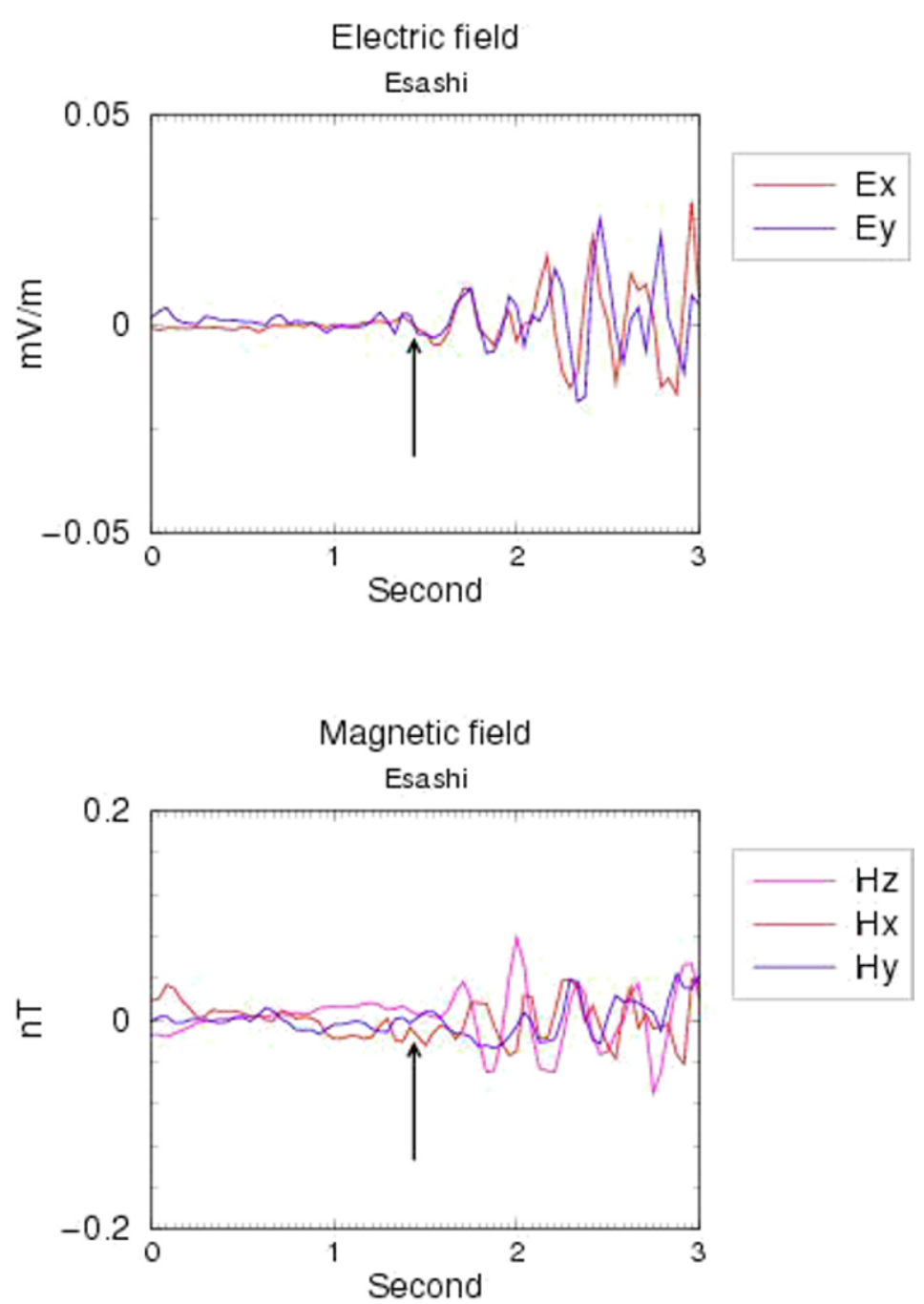

Fig. 7. Close-up views of Fig. 5. The arrow indicates the estimated P-wave arrival time for the M6.4 earthquake. Small tick marks indicate the sampling times of the electric and the magnetic fields.

indicates the estimated P-wave arrival time at the MT sites. In each figure, signals appear only after the arrival of P-wave, contrary to the case of the 1999 Izmit earthquake. The $H_{x}$ (35 degrees west from the magnetic north) component of the magnetic field at Mizusawa may have started to change slightly earlier than the P-wave, but the possible precursory time is too short to be significant, if we take into account possible errors of P-wave arrival time.

\subsection{The M6.4 earthquake of July 26}

In this case, the hypocentral distance is nearly the same as the case for the M7.1 earthquake, but the magnitude is smaller, suggesting smaller electric and magnetic signals. Nonetheless we attempted to examine the signals due to the seismic dynamo effect in order to show more examples of the effect.

Figure 5 shows the electric and the magnetic field variations at the MT stations. We can clearly see the same characteristics in the amplitudes of the electric and the magnetic fields. The magnetic field is also clipped at Mizusawa, but we can see clear magnetic signals at Esashi. These variations are again very similar to the seismic records at SMT as shown in Fig. 6. The ground velocity is one order of magnitude smaller than the case of the M7.1 earthquake (see
Fig. 3). Accordingly, the amplitudes of electric and magnetic field variations are smaller, implying that signals precursory to the P-wave are unlikely to be observed. In fact, the signals are also smaller after the P-wave arrival, as seen in Fig. 7.

\section{Conclusions}

Through the MT data obtained at Mizusawa and Esashi for the M7.1 earthquake of 26 May 2003 and for the M6.4 earthquake of 26 July 2003, we obtained the following conclusions.

(1) The amplitudes of electric and magnetic field variations due to the seismic dynamo effect are controlled by the local resistivity structure, indicating that the effect is an electromagnetic induction phenomenon.

(2) No clear electric and magnetic signals precursory to the P-wave arrival could be detected even for the M7.1 earthquake. However, in view of the possibility of a slight signal in one component of the magnetic field, we may infer the lower bound for precursory signals; for an M7.1 earthquake with the hypocentral distance of $100 \mathrm{~km}$, precursory signals are unlikely to be detected at the present MT sites, although more quantitative argument should be made in terms of the ground velocity. 
As a final remark, we raise one comment: whether signals precursory to the P-wave arrival can be observed depend on the level of background electric and magnetic noises. If carefully designed experiments are made, such as measurements in the deep bore-hole, the above bound may be lowered considerably.

Acknowledgments. We used the MT data acquired at the Mizusawa and the Esashi observatories of the Geographical Survey Institute. We thank the staff of the Mizusawa Geodetic Observatory. We also used the seismic data obtained at three Hi-net stations, SMT, TOU and KGS, in Iwate Prefecture. We are thankful to Dr. Mizuho Ishida and the data center of the Disaster Prevention Research Institute for the seismic data. We are also thankful to our JMA colleagues for determination of arrival times at the Mizusawa and Esashi observatories. We thank Stephen Park and an anonymous referee for valuable comments.

\section{References}

Honkura, Y., A. M. Işikara, N. Oshiman, A. Ito, B. Üçer, S. Bariş, M. Tunçer, M. Matsushima, R. Pektaş, C. Çelik, B. Tank, F. Takahashi, M. Nakanishi, R. Yoshimura, Y. Ikeda, and T. Komut, Preliminary results of multidisciplinary observations before, during and after the Kocaeli (Izmit) earthquake in the western part of the North Anatolian Fault Zone, Earth Planets Space, 52, 293-298, 2000.

Honkura, Y., M. Matsushima, N. Oshiman, M. K. Tunçer, Ş. Bariş, A. Ito, Y. Iio, and A. M. Işikara, Small electric and magnetic signals observed before the arrival of seismic wave, Earth Planets Space, 54, e9-e12, 2002.

Matsushima, M., Y. Honkura, N. Oshiman, S. Baris, M. K. Tuncer, S. B. Tank, C. Cerik, F. Takahashi, M. Nakanishi, R. Yoshimura, R. Pektas, T. Komut, E. Tolak, A. Ito, Y. Iio, and A. M. Isikara, Seimoelecromagnetic effect associated with the Izmit earthquake and its aftershocks, Bull. Seismol. Soc. Am., 92, 350-360, 2002.

Satoh, H., T. Yutsudo, T. Kadowaki, M. Ishihara, and S. Fujiwara, Monitoring of crustal resistivity variations using a stationary wideband MT measurement system, Bull. Geograph. Survey Inst., 101, 23-32, 2003 (in Japanese).

Ujihara, N., Y. Honkura, and Y. Ogawa, Electric and magnetic field variations arising from the seismic dynamo effect for aftershocks of the M7.1 earthquake of 26 May 2003 off Miyagi Prefecture, NE Japan, Earth Planets Space, 55, 115-124, 2004.

Y. Honkura (e-mail: yhonkura@geo.titech.ac.jp), H. Satoh (e-mail: satou-h@aist.go.jp), and N. Ujihara (e-mail: nujihara@geo.titech.ac.jp) 